\title{
Too big? A review of methods for removing large endometrial polyps in office minihysteroscopy - broadening the indications for the procedure in the COVID-19 pandemic
}

\author{
Magdalena M. Biela ${ }^{1}$, Jacek Doniec ${ }^{2}$, Paweł Kamiński ${ }^{1}$ \\ ${ }^{1}$ Department of Gynecology and Oncological Gynecology, Military Institute of Medicine, Warsaw, Poland \\ ${ }^{2}$ Robotic Surgery Center, Military Institute of Medicine, Warsaw, Poland
}

Videosurgery Miniinv 2022; 17 (1): 104-109

DOI: https://doi.org/10.5114/wiitm.2021.107762

\begin{abstract}
Hysteroscopy is the gold standard for the diagnosis and treatment of endometrial polyps. For small polyps (less than $2 \mathrm{~cm}$ ) minihysteroscopy can be performed in an office setting. Patients with polyps larger than $2 \mathrm{~cm}$ are usually referred for a standard resectoscope procedure in the operation room (OR) under general anaesthesia. Those patients are exposed to longer hospital stay and possible complications of the anaesthesia. Furthermore, they usually have longer contact with many medical staff members. Limiting the time of contact as well as the number of staff involved in the procedure is particularly important during the COVID-19 pandemic. For this reason, minihysteroscopy in an office setting should be the first choice in every possible indication. We present the methods that may be useful for removing even large polyps in minihysteroscopy. The advantages and disadvantages of every procedure are discussed.
\end{abstract}

Key words: hysteroscopy, polyp, minihysteroscopy, Cryoprobe, mini-resectoscope, Hysteroscopic Tissue Removal system.

\section{Introduction}

Endometrial polyps are among the most common intrauterine pathologies. They can be found in both pre- and postmenopausal women and can be asymptomatic [1] or cause abnormal uterine bleeding (AUB) or infertility [2]. Most of the polyps are benign pathologies but in rare cases endometrial hyperplasia, atypia, or even cancer can be found. Furthermore, most of the uterine benign polyps will persist if left untreated, while only small polyps (less than $5 \mathrm{~mm}$ ) may spontaneously regress [3]. For these reasons, patients with diagnosed uterine cavity polyps are usually offered a procedure to remove the lesion, with a histopathological examination of the specimen.

The size and localization of the polyp are usually evaluated before the procedure in transvaginal so- nography (TVS) and, depending on the results, the patient is scheduled for a particular kind of surgery. For many years, the gold standard for the diagnosis and treatment of endometrial polyps has been hysteroscopy [4]. Classic hysteroscopy is performed using resectoscopes, which are usually $8-9 \mathrm{~mm}$ of diameter. This kind of procedure requires $O R$ and general anaesthesia due to the necessity of painful cervix dilatation. Thanks to the minimization of the equipment and the introduction of the "no-touch" technique called vaginoscopy, office hysteroscopy can be successfully preformed in an outpatient setting nowadays [5]. Initially, only diagnostic procedures were conducted without anaesthesia, but nowadays a wide range of $5 \mathrm{Fr}$ instruments also allow operative hysteroscopy to be performed in an office setting [6]. The size and localization of the 
polyp are usually the criteria for choosing the appropriate surgery method. Muzii et al. proposed an algorithm for the treatment of endometrial polyps, in which for small and non-fundal polyps a minihysteroscopic excision is preferable, while for polyps $>2 \mathrm{~cm}$ or with a fundal implant, an operative resectoscopy appears to be the technique of choice [7]. Nevertheless, in the COVID-19 pandemic, the special benefits of minihysteroscopy seem to outweigh the disadvantages associated with the longer duration of the procedure. For this reason, even polyps bigger than $2 \mathrm{~cm}$ should be treated in an outpatient setting, using hysteroscopes of $5 \mathrm{~mm}$ or less, if possible.

\section{Aim}

The aim of the review is to present the available methods of removing large polyps using office minihysteroscopy. Broadening the indication for office hysteroscopic procedures is especially important in the COVID-19 pandemic and may help to limit the risk of transmission of the virus. We present the techniques of the surgery using standard $5 \mathrm{Fr}$ hysteroscopic tools, but also with newer devices: the Hysteroscopic Tissue Removal System (HTRs), the miniresectoscope, and the Cryoprobe.

\section{Material and methods}

A brief review of methods for removing large endometrial polyps in office hysteroscopy was carried out taking into account the authors' extensive experience in such procedures. The advantages and disadvantages of every method were described according to the current literature on the subject. The authors also presented their own data on the use of a new tool for minihysteroscopy - the Cryoprobe.

\section{Results}

A wide range of minihysteroscopes, about $5 \mathrm{~mm}$ or less in diameter, is available nowadays, and all of them are suitable for performing office procedures without anaesthesia. Every kind of hysteroscope or hysteroscopic tool has its specific advantages and disadvantages. Choosing the best option for each patient should be preceded by an evaluation of the size, localization, and structure of the polyp, but also the anatomy of the patient should be considered. Additionally, in the COVID-19 pandemic, the epidemiological aspects must be considered while qual- ifying the patient for a particular procedure. All the available hysteroscopic devices and tools are presented in Table I and are discussed below.

1. Office operative minihysteroscopes with the Continuous Flow system and an operative 5 - Fr canal (approximately $1.6 \mathrm{~mm}$ ). Usually oval in shape, ideal for atraumatic insertion of the scope into the cervix [8]. They are perfect for 'see and treat' procedures - the same tool is used for diagnosis and treatment of the lesion. For polypectomy, various available $5-\mathrm{Fr}$ tools can be used in minihysteroscopy, but not all of them are suitable for removing big polyps.

Tools not useful for large polyps:

- mechanical tools: grasping forceps, scissors are not very useful for large lesions, because of their delicate construction. These tools can be easily broken during the procedure. Moreover, excision of a large polyp and especially the extraction of the material from the uterine cavity can be very difficult using only mechanical tools.

- laser - diode lasers are used worldwide in hysteroscopy. The authors have used mostly a $1470 \mathrm{~nm}$ laser (Metrum Cryoflex, Poland) in office hysteroscopy procedures since 2014. One of the most important features of the $1470 \mathrm{~nm}$ laser is the very high absorption of energy by water. This makes it a very safe device to use for precise contact vaporization of the uterine cavity pathologies (Photo 1). Very low energy is sufficient to achieve the effect of vaporization, so the tool is safe for the patient. Nevertheless, it is useful primarily for small lesions, because of the long time needed for a complete vaporization of a large polyp. Moreover, we can only

Table I. Devices and tools for minihysteroscopy

\begin{tabular}{|c|c|c|}
\hline Device type & Tool & $\begin{array}{c}\text { Useful for large } \\
\text { polyps }\end{array}$ \\
\hline \multirow{4}{*}{$\begin{array}{l}\text { Office operative } \\
\text { minihysteroscope }\end{array}$} & Mechanical tools & $x$ \\
\hline & Laser & $x$ \\
\hline & Electric tools & $\checkmark$ \\
\hline & Cryoprobe & $\checkmark$ \\
\hline $\begin{array}{l}\text { Hysteroscopic } \\
\text { Tissue Removal } \\
\text { system (HTRs) }\end{array}$ & & $\checkmark$ \\
\hline Mini-resectoscope & & $\checkmark$ \\
\hline
\end{tabular}



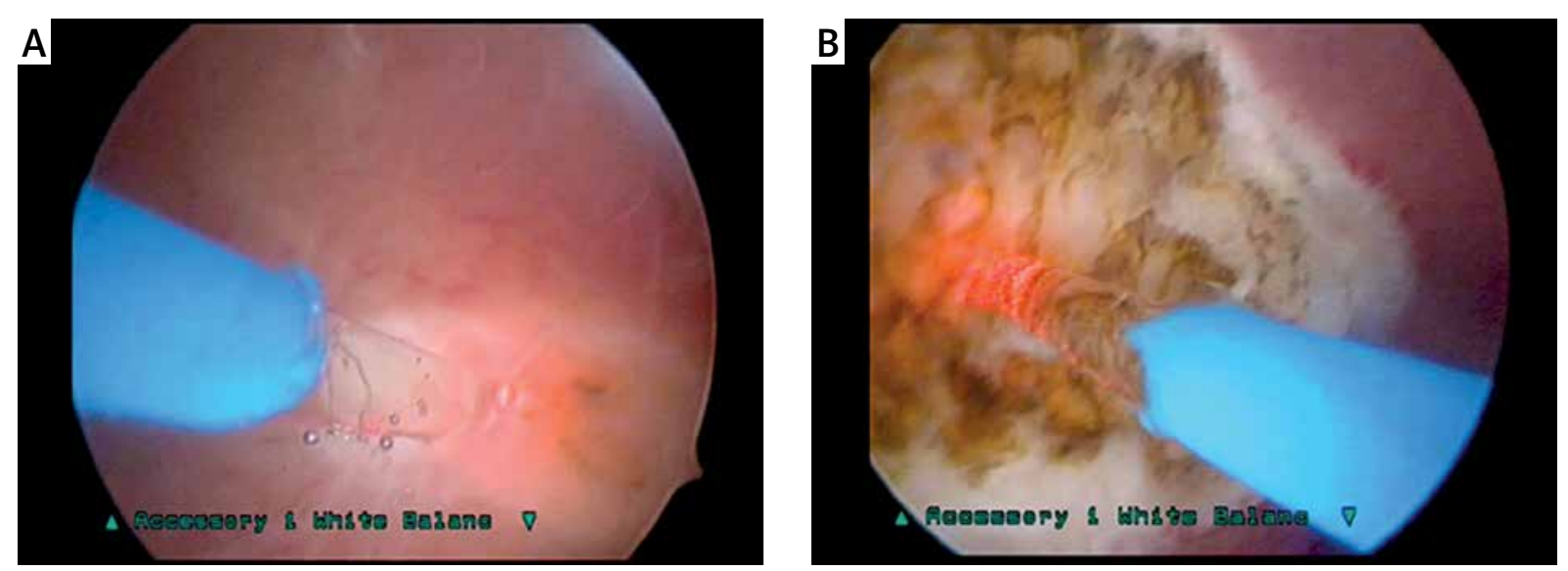

Photo 1. Vaporization of the uterine lesion with a $1470 \mathrm{~nm}$ laser in minihysteroscopy

treat unsuspicious lesions, because no tissue is collected for pathology examination [9].

Tools useful for large polyps:

- electric tools: bipolar electrodes, as opposed to monopolar ones, can be used with normal saline as a distending medium, reducing the consequences of fluid intravasation [7]. At present, this is the most popular and most widely used tool for minihysteroscopic polypectomy. In the case of large polyps, the slicing technique is used: the polyp is cut into smaller parts - a slice from the left side and a slice from the right side. Finally, the base of the polyp is cut off. Every slice is removed from the uterine cavity one by one with the grasping forceps [10]. Taking out the fragments of a large polyp is sometimes the most difficult part of the procedure. Glandular polyps are often delicate and the tissue tears while being pulled with a grasper. On the other hand, hard fragments of fibrous polyps are difficult to hold with the grasping tools, which can slide off the polyp surface, making their removal difficult, consequently prolonging the procedure. In some cases, cutting off the base before slicing the polyp can make the procedure less painful for the patient, although cutting an unattached polyp is more difficult for the surgeon.

- Cryoprobe - an innovative, reusable cryoadhesion probe, 4FR diameter, designed in our department. The use of a low temperature at the tip of the tool allows one to grasp and remove tissue fragments [11]. Because of its durability and strong connection with the tissue, also large polyps/fragments can be easily removed from the uterine cavity, which significantly shortens the duration of the hysteroscopic procedure [12]. Moreover, some small polyps can be directly attached to the probe, twisted during freezing, and extracted without using any other hysteroscopic instrument (Photo 2).

2. Hysteroscopic Tissue Removal systems (HTRs) tools based on the mechanical removal of intrauterine lesions. In recent years, a few companies have developed tools of slightly different shapes, but based on the same working rule. The tissue is sucked into the cutting window and cut into small fragments by a rotating blade. The system aspirates the removed tissue, so there is no need to take out and insert the hysteroscope repeatedly. The treatment of large (over $20 \mathrm{~mm}$ ) polyps with HTRs is feasible and well tolerated in an office setting [13]. When compared with bipolar electrical resection, HTRs are faster, have a higher success rate for complete polypectomy, and require a shorter learning curve [14]. In addition, the procedure is less painful for patients than BE polypectomy [10]. The disadvantage of the device is the relatively high cost and the limited possibilities of excising lesions situated in the fundus of the uterus. Nevertheless, the intrauterine morcellator is gradually becoming more popular in outpatient operative minihysteroscopy, also because of the short learning curve. HTRs are also useful for the management of type 0 and type 1 submucosal myomas in the office setting, in contrast to traditional resectoscopy, which requires general anaesthesia [15] (Photo 3).

3. Mini-resectoscopes - the smallest available continuous-flow resectoscopic systems, 16F diameter. The technique of miniresectoscopic surgery involves a serial resection (slicing) of the polyp, 

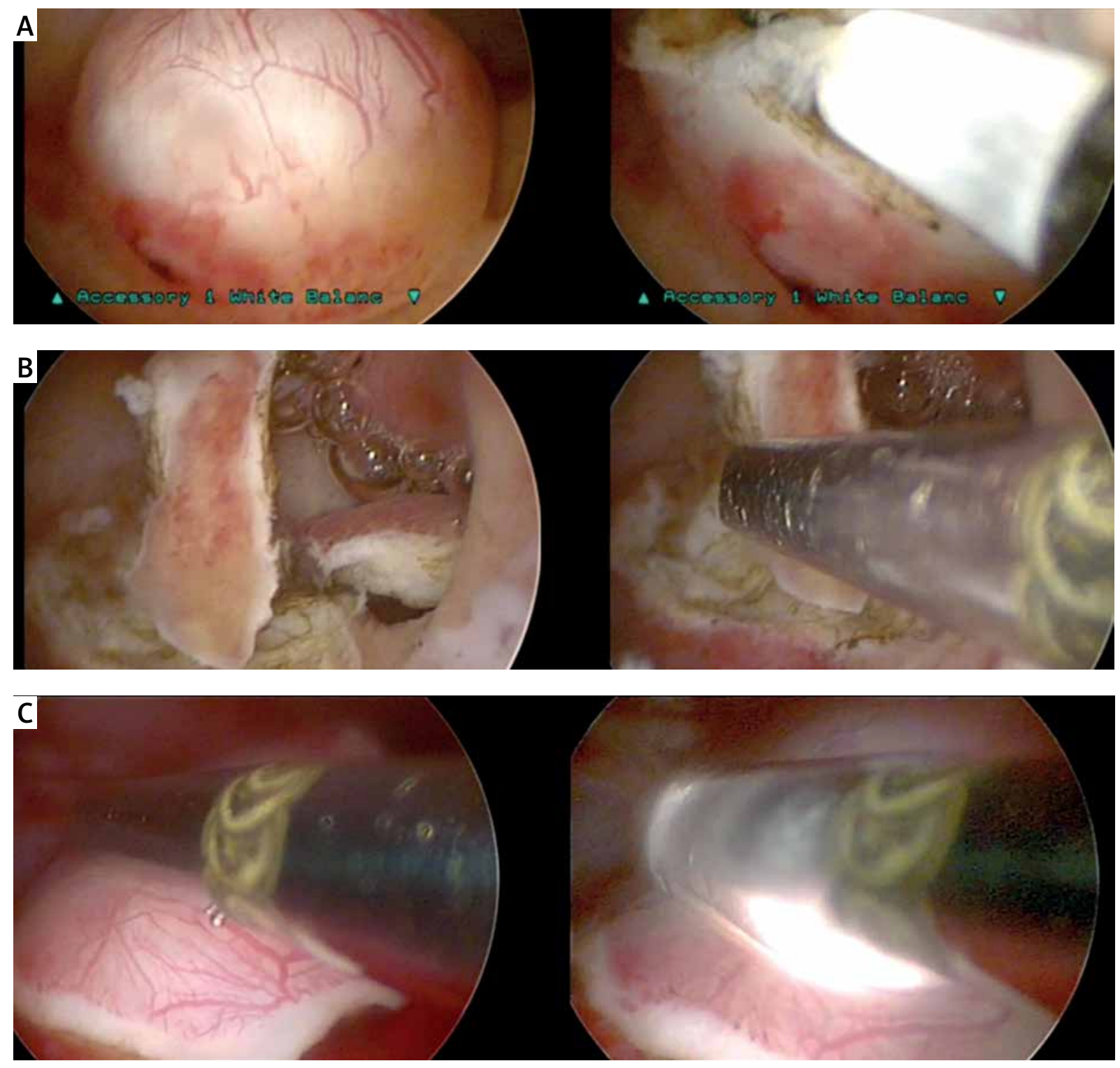

Photo 2. Slicing the polyp with a bipolar electrode and removing fragments with a Cryoprobe

starting with its free end and advancing toward its base of implantation or, in the case of a pedunculated endometrial polyp, resection of the pedicle and extraction of the polyp [16]. This type of hysteroscope is suitable for resection of large polyps, even those situated in the uterine fundus or tubal ostium. The only problem for office procedures may be in removing of the slices from the uterine cavity. Also, the circular profile of the mini-resectoscope makes it more traumatic for the cervical canal compared to the oval office Bettocchi continuous-flow operative hysteroscope. The in-office miniresectoscopy can be also used for the treatment of the submucosal myomas and for the isthmoplasty procedures [17].

\section{Discussion}

Although it is generally believed that office hysteroscopy is suitable only for polyps smaller than $2 \mathrm{~cm}$, proper selection and application of one of the presented methods extends the indications for the procedure.

In the COVID-19 pandemic, when for epidemiological reasons minimal interpersonal contact and minimal hospitalization time are required, minihysteroscopy performed in an office setting seems to be 


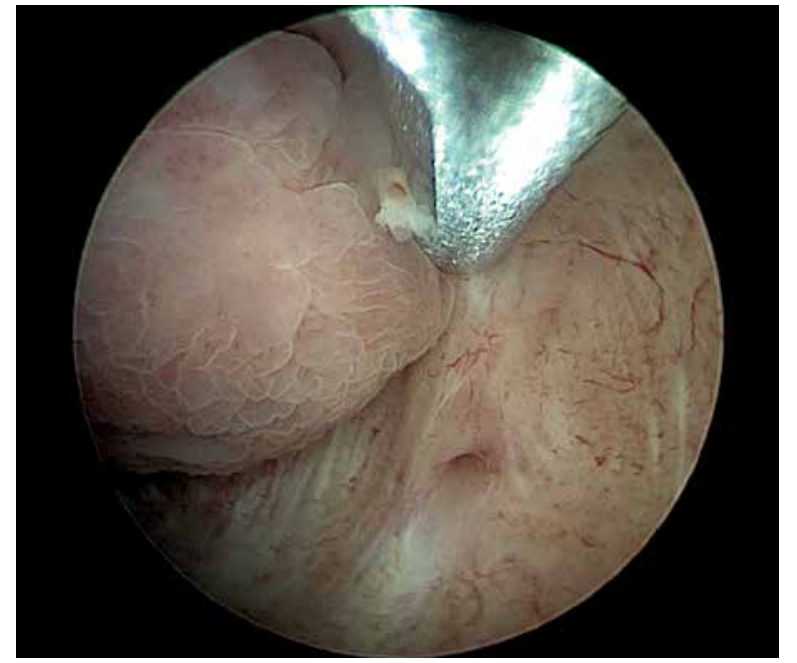

Photo 3. Hysteroscopic Tissue Removal system polypectomy

the best option for patients with endometrial polyps, also with large ones. Office hysteroscopies are usually performed by just one surgeon, with the assistance of one nurse, and no hospital admission procedure is needed. For these reasons, the outpatient setting is relatively safe for the patient as well as for the staff. An additional advantage is no need for anaesthesia, so the anaesthetic team may be redirected to other departments of the hospital, where they are essential. Office hysteroscopy does not require the use of mechanical ventilation and has no impact on the hospital's Intensive Unit Care capacity [18].

\section{Conclusions}

For office polypectomy of large endometrial polyps, mini-resectoscopes and hysteroscopic tissue removal systems, as well as operative minihysteroscopes, could be used. In minihysteroscopy, a slicing technique with a bipolar electrode may be performed. In the case of difficulties extracting large tissue fragments, the newly introduced Cryoprobe seems to be the best option. Each of the methods described above has its specific applications, but thanks to their mutual complementation, we are now able to excise almost every lesion from the uterine cavity in an outpatient setting [19].

\section{Conflict of interest}

Metrum CryoFlex, Poland provided the $1470 \mathrm{~nm}$ laser generator and the Cryoprobe device free of charge for clinical trials.

\section{References}

1. DeWaay DJ, Syrop CH, Nygaard IE, et al. Natural history of uterine polyps and leiomyomata. Obstet Gynecol 2002; 100: 3-7.

2. Salim S, Won H, Nesbitt-Hawes E, et al. Diagnosis and management of endometrial polyps: a critical review of the literature. J Minim Invasive Gynecol 2011; 18: 569-81.

3. Lieng M, Istre O, Sandvik L, Qvigstad E. Prevalence, 1-year regression rate, and clinical significance of asymptomatic endometrial polyps: cross-sectional study. J Minim Invasive Gynecol 2009; 16: 465-71.

4. American Association of Gynecologic Laparoscopists. AAGL practice report: Practice guidelines for the diagnosis and management of endometrial polyps. J Minim Invasive Gynecol 2012; 19: 3-10.

5. Bettocchi S. New era of office hysteroscopy. J Am Assoc Gynecol Laparosc 1996; 3 (4 Suppl): S4.

6. Bettocchi S, Ceci O, Di Venere R, et al. Advanced operative office hysteroscopy without anaesthesia: analysis of 501 cases treated with a 5 Fr. bipolar electrode. Hum Reprod 2002; 17: 2435-8.

7. Muzii L, Bellati F, Pernice M, et al. Resectoscopic versus bipolar electrode excision of endometrial polyps: a randomized study. Fertil Steril 2007; 87: 909-17.

8. Bettocchi S, Nappi L, Ceci O, Selvaggi L. What does 'diagnostic hysteroscopy' mean today? The role of the new techniques. Curr Opin Obstet Gynecol 2003; 15: 303-8.

9. Doniec J, Biela M, Szafarowska M, et al. Destruction of the uterine cavity pathologies using the $1470 \mathrm{~nm}$ laser. Poster Session, $23^{\text {rd }}$ Annual ESGE Congress 2014, Brussels.

10. Ceci O, Franchini M, Cardinale S, et al. Comparison of endometrial polyp recurrence in fertile women after office hysteroscopic endometrial polypectomy using two widely spread techniques. J Obstet Gynaecol Res 2020; 46: 2084-91.

11. Sobociński K, Doniec J, Biela M, et al. Usefulness of Cryoprobe in office hysteroscopy for removal of polyps and myomas. Biomed Res Int 2018; 2018: 7104892.

12. Biela M, Doniec J. The new, easy and fast method of removing large polyps from the uterine cavity in minihysteroscopy. BEST VIDEO session, ESGE 25th Annual Congress 2016, Brusselss.

13. Ceci O, Franchini M, Cannone R, et al. Office treatment of large endometrial polyps using truclear 5C: feasibility and acceptability. J Obstet Gynaecol Res 2019; 45: 626-33.

14. Pampalona JR, Bastos MD, Moreno GM, et al. A comparison of hysteroscopic mechanical tissue removal with bipolar electrical resection for the management of endometrial polyps in an ambulatory care setting: preliminary results. J Minim Invasive Gynecol 2015; 22: 439-45.

15. Vitale SG, Sapia F, Rapisarda AMC, et al. Hysteroscopic morcellation of submucous myomas: a systematic review. Biomed Res Int 2017; 2017: 6848250.

16. Dealberti D, Riboni F, Cosma S, et al. Feasibility and acceptability of office-based polypectomy with a 16F mini-resectoscope: a multicenter clinical study. J Minim Invasive Gynecol 2016; 23 : 418-24.

17. Casaido P, Gubbini G, Franchini M, et al. Comparison of hysteroscopic cesarean scar defect repair with $26 \mathrm{Fr}$ resectoscope and 16 Fr miniresectoscope: a prospective pilot study. J Minim Invasive Gynecol 2021; 28: 314-9. 
18. Vitale SG, Carugno J, Riemma G, et al. The role of hysteroscopy during COVID-19 outbreak: safeguarding lives and saving resources. Int J Gynecol Obstet 2020; 150: 256-8.

19. Biela M, Doniec J, Szafarowska M, et al. Is every patient eligible to have an office hysteroscopy? A retrospective analysis of 1301 procedures. Videosurgery Miniinv 2020; 15: 337-45.

Received: 28.01.2021, accepted: 13.05.2021. 